\title{
Sensitivity and specificity of three hearing screening protocols in the school setting
}

Aryelly Dayane da Silva Nunes
https://orcid.org/0000-0002-3814-2675

Rhadimylla Nágila Pereira ${ }^{2}$

https://orcid.org/0000-0001-8204-9104

Antonio Pereira Junior ${ }^{3}$ https://orcid.org/0000-0002-0808-1058

Isabelle Ribeiro Barbosa ${ }^{4}$ https://orcid.org/0000-0002-1385-2849

Sheila Andreoli Balen ${ }^{5}$ https://orcid.org/0000-0003-1353-4362

Universidade Federal do Rio Grande do Norte - UFRN, Programa de Pós Graduação em Saúde Coletiva, Natal, Rio Grande do Norte, Brasil.

2 Prefeitura de Natal, Natal, Rio Grande do Norte, Brasil.

3 Universidade Federal do Pará - UFPA, Instituto de Tecnologia, Laboratório de Processamento de Sinais, Belém, Pará, Brasil.

Universidade Federal do Rio Grande do Norte - UFRN, Faculdade de Ciências da Saúde do Trairi, Santa Cruz, Rio Grande do Norte, Brasil.

${ }^{5}$ Universidade Federal do Rio Grande do Norte - UFRN, Hospital Universitário

Onofre Lopes, Laboratório de Inovação Tecnológica em Saúde - LAIS,

Departamento de Fonoaudiologia, Natal, Rio Grande do Norte, Brasil.

The study was developed in the Federal University of Rio Grande do Norte - Natal, Rio Grande do Norte, Brazil.

Research support source: "This study was financed in part by the Coordenação de Aperfeiçoamento de Pessoal de Nível Superior - Brasil (CAPES) - Finance Code 001".

Conflict of interests: Nonexistent

\section{(c) (i)}

Received on: June 10, 2019

Accepted on: August 24, 2020

Corresponding address:

Sheila Andreoli Balen

Universidade Federal do Rio Grande do

Norte, Centro de Ciências da Saúde

Rua Desembargador Hemetério

Fernandes 102, 1162 , Tirol

CEP: 59015-110 - Natal, Rio Grande

do Norte, Brasil

E-mail: sheila@sheilabalen.com

\section{ABSTRACT}

Objective: to evaluate the sensitivity and specificity of three hearing screening protocols: audiometry, tympanometry, and transient evoked otoacoustic emissions (TEOAE).

Methods: a cross-sectional study comprising 70 schoolchildren aged 6-14 years old $(9.9 \pm 2)$. All participants underwent a complete audiological evaluation and screening procedures. Procedures were compared regarding sensitivity, specificity, and positive and negative predictive values.

Results: sensitivity and specificity were, respectively, $64.71 \%$ and $66.04 \%$ for audiometry, $64.71 \%$ and $73.58 \%$ for tympanometry, and $66.67 \%$ and $78.85 \%$ for TEOAE. The positive and negative predictive values were $37.93 \%$ and $14.63 \%$ for audiometry, $44 \%$ and $13.33 \%$ for tympanometry, and $52.17 \%$ and $12.77 \%$ for TEOAE.

Conclusions: in the school setting, TEOAE stands out from the two other screening protocols, in all measures regarding sensitivity, accuracy, and predictive values.

Keywords: Hearing; Mass Screening; Child; School; Hearing Loss 


\section{INTRODUCTION}

Hearing enables a child's contact with the world of sound and language, in particular'. The acquisition of hearing skills drives both oral and written language development ${ }^{1,2}$. Hearing loss has a deleterious effect on speech and language development, as well as on academic performance ${ }^{1,3}$, also hindering social, emotional, and cognitive developing skills. The larger the degree of hearing impairment, the more difficult it is to perceive and discriminate speech, hence, the larger the language handicaps ${ }^{2}$.

The World Health Organization (WHO) estimates 466.46 million people have hearing loss worldwide, of which 34 million are children ${ }^{4}$. Latin America and the Caribbean has 40.19 million people ${ }^{4}$, and in Brazil about 9.8 million are hearing-impaired5 $5^{5}$. There is a close relationship between the prevalence of hearing loss, family income, and parents' education level ${ }^{4}$. A recent study ${ }^{6}$ showed a prevalence of $16.49 \%$ of children with hearing loss, mostly unilateral, mild, and in rural areas. Another study ${ }^{7}$ noted the great variability in the prevalence of hearing loss in children, from $1.4 \%$ (regarding 29 countries) to $17.5 \%$ (Netherlands). The same was found in Africa ${ }^{8}$ and evidenced in a systematic review ${ }^{9}$. Although there is variability, it is evident that hearing loss in children is common ${ }^{7}$ and has important impacts on their development.

Children with hearing loss may face many challenges in the school setting due to attention deficits, difficulty memorizing and understanding what is said, impaired working memory, and lack of interest and concentration ${ }^{10}$. It is also common in the school context for children with mild hearing loss to suffer from hearing discomfort, tinnitus, and worse quality of life ${ }^{11}$. Mild hearing loss can also affect school performance ${ }^{12}$.

Thus, it is essential to invest in early detection, diagnosis, and rehabilitation of hearing impairment by creating a hearing health promotion programs for schoolchildren ${ }^{6,12}$. For children under 15 years of age, $60 \%$ of hearing impairment cases result from preventable causes, $31 \%$ of which are related to infections such as mumps, measles, rubella, meningitis, cytomegalovirus infections, and chronic otitis media ${ }^{4}$.

Conductive hearing losses are the most common cause of hearing impairment in school-age children ${ }^{13,14}$ and are simple to correct. Tympanograms without peak compliance or a negative one were the most common among younger children ( 4 to 10 years old), while tympanograms suggesting normal middle ear function were the most common for children over 10 years old ${ }^{13}$.
The gold standard for hearing screening of schoolchildren is pure tone audiometry ${ }^{15}$. Either acoustic immittance or otoscopy performed by otorhinolaryngologist is usually recommended to detect middle ear alterations in schoolchildren ${ }^{15}$. However, other methods with objective response capture such as transient evoked otoacoustic emissions (TEOAE) and distortion product otoacoustic emissions (DPOAE), both of which are widely used in neonatal hearing screening ${ }^{16}$, may prove useful with preschoolers and schoolchildren ${ }^{17,18}$ when it is not possible to perform pure tone hearing screening. Tympanometric screening is recommended for younger children such as preschoolers or as an alternative option after failure in pure tone audiometry or otoacoustic emission screenings ${ }^{15}$.

Studies have shown a diversity of methods used for hearing screening in schools ${ }^{7,9,19,20}$, which vary from the combination of clinical procedures with different pass-fail criteria ${ }^{7,9,19,20}$ to the development of new tools ${ }^{21,22}$ and use screening methods varying within the same country ${ }^{23}$ as evidenced by the next examples. A study with schoolchildren between 6 and 9 years old combined TEOAE, DPOAE, and tympanometry procedures $^{20}$. Researchers screened children from 6 to 8 years old using audiometric screening at 1,2 , and $4 \mathrm{kHz}$ at $20 \mathrm{~dB}$ with type $\mathrm{A}$ tympanometric curve and presence of ipsilateral acoustic reflexes at $0.5,1,2$, and $4 \mathrm{kHz}^{19}$. The proposition of a new hearing screening strategy in schoolchildren based on evidence highlights the use of DPOAE as the first technique, and of tympanometry, audiometric screening at $20 \mathrm{dBNA}$, acoustic reflex, and otoscopy to those who fail ${ }^{24}$.

In Brazil studies indicate that the most frequent type of hearing loss is conductive $e^{17,19,20}$. The country recommends evaluating the hearing acuity of schoolage children and adolescents ${ }^{25}$. It is essential to use methods that are sensitive and specific to this age group, as well as safe diagnostic techniques.

Hence, the purpose of this study is to investigate the sensitivity and specificity of audiometric, tympanometric, and TEOAE screenings when applied to the hearing screening of school-age children and adolescents.

\section{METHODS}

This cross-sectional study was approved by Federal University of Rio Grande do Norte (UFRN) Research Ethics Committee (030/11-P-CEP/UFRN), Brazil. The subjects were $1821^{\text {st }}-5^{\text {th }}$ grade students enrolled in a public school in Natal, RN, Brazil. The sample was 
calculated with an estimated proportion of hearing loss of $16.8 \%{ }^{26}$, margin of error and non-response rate of $5 \%$, resulting in 104 students. The entire population was invited to the research. We obtained the informed consent from the subjects' parents or guardians. The inclusion criteria were performing all proposed procedures on the same day, being healthy enough to perform the procedures and having no blockage of the ear canal. The study was performed on consecutive Saturdays from March to September 2012, due to the low noise level required by the procedures. Eighty students came up for the study, of which three special needs students were unable to complete the evaluation, and seven dropped out of the study. The sample thus consisted of 70 students with ages between 6 and 14 years old $(9.9 \pm 2.0)$, with 36 males and 34 females.

We submitted all subjects to meatoscopy, audiometric screening, tympanometric screening, transient evoked otoacoustic emissions test (TEOAE) screening, and a complete audiological evaluation, which is the gold standard procedure in this type of research. We measured the intensity of environmental noise using an ICEL Manaus DL-4020 decibel meter. We performed meatoscopy with a Heidji otoscope to identify conditions for performing the procedures. The purpose of pure tone audiometry is to detect hearing alterations. It is the gold standard for hearing screening in schoolchildren ${ }^{15}$.

We performed pure tone detection using an Interacoustic ${ }^{\circledR}$ AD229 audiometer with descending method to establish the threshold, considering as the pass criterion the threshold for at least $20 \mathrm{~dB} N A$ at three tested frequencies (at 1000, 2000, and $4000 \mathrm{~Hz}$ ) for both ears ${ }^{15}$. The tympanometric screening aimed at verifying middle ear integrity and the mobility of the tympano-ossicular system. We used the Interacoustic ${ }^{\circledR}$ AT 235 immittance meter with a base tone of $226 \mathrm{~Hz}$ set to the automatic mode. We considered the tympanometric gradient of at least $0.2 \mathrm{ml}$ in both ears as the pass criterion. We performed the TEOAE test with the Otoportanmic $\AA$ Otoport with frequencies from 1000 to $4000 \mathrm{~Hz}$, and tests were interrupted whenever the equipment emitted a detection alert. The adopted pass criterion was the presence of TEOAE in at least three consecutive frequency bands at a signal-to-noise ratio of at least $3 \mathrm{~dB}$ and over $50 \%$ reproducibility in both ears $^{27}$.

To establish complete audiologic evaluation results we performed pure tone audiometry in an acoustic booth with an Interacoustic AD229 audiometer and TDH-39 earphones to obtain the speech recognition threshold (SRT) and the speech recognition index (SRI). Normal hearing was defined when the threshold was $15 \mathrm{~dB}$ or less ${ }^{28}, \mathrm{SRI}$ at least $92 \%$, and SRT consistent with $0.5,1$, and $2 \mathrm{KHz}$ means. We performed the tympanometry using the Interacoustic AT235 impedance meter set to the automatic mode, with a pressure of +200 to $-400 \mathrm{daPa}$ and a probe tone of $226 \mathrm{~Hz}$. By using these procedures - pure tone audiometry, SRT, SRI and tympanometry, we were able to identify the presence or absence of hearing loss. In order to avoid ear laterality effect, we began the procedures alternately for every child and we blinded evaluators to the results of the other procedures. In case of screening failure, the subject was retested immediately after removing the earphones or olives ${ }^{15}$. Subjects who presented altered results were referred to otorhinolaryngological evaluation. To perform the accuracy analysis, the procedures were analyzed and compared relating the gold standard (pure tone audiometry) with the pass-fail results of each screening procedure to establish the values for sensitivity, specificity, and positive and negative predictive values.

\section{RESULTS}

The sample loss was $32.7 \%$. Among the participants $(\mathrm{N}=70), 53(75.72 \%)$ had normal hearing and 17 (24.28\%) presented hearing loss, of which 11 (15.71\%) were conductive and 6 (8.57\%) were sensorineural losses (Figure 1). Amid the students with hearing loss, 7 (41.17\%) were bilateral and 10 (58.83\%) were unilateral, varying from mild to moderate impairments. 


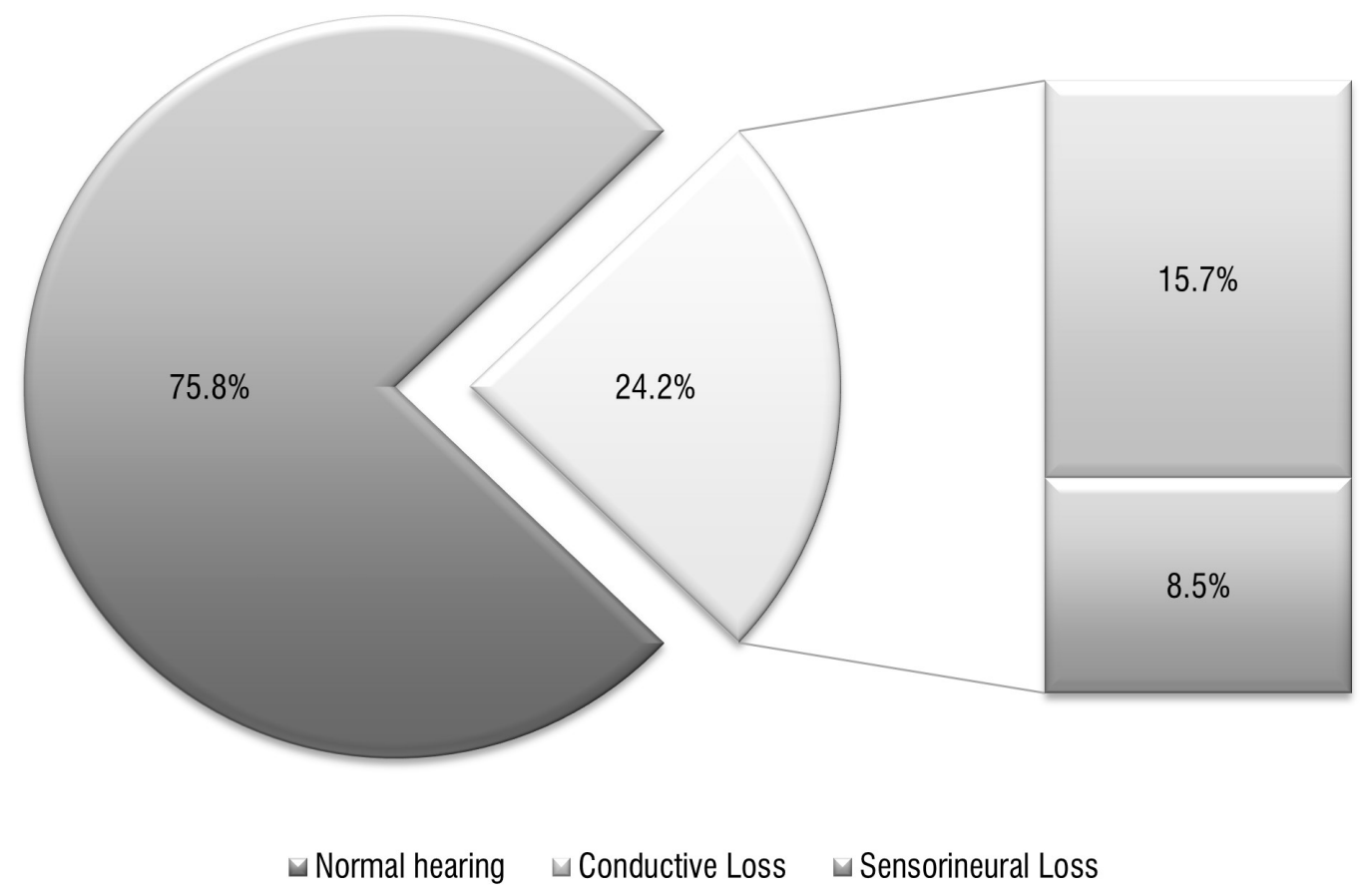

Figure 1. Occurrence of each type of hearing loss found in the study

The screening procedures showed close numerical values (Figure 2). We compared the results obtained to the gold standard to calculate validity. Regarding sensitivity, all three tested screening procedures showed close values, with greater variation in specificity values. When comparing values of sensitivity, specificity, predictive values, and accuracy, we obtained better results overall for the TEOAE (Table 1).
The noise level during the procedures ranged from 39.70 to $61.70 \mathrm{~dB}(49.16 \pm 5.37 \mathrm{~dB})$ for liminal tone audiometry, SRT and SRI, and from 44.8 to 57.4 $\mathrm{dB}(48.50 \pm 6.00 \mathrm{~dB})$ for transient evoked otoacoustic emissions (TEOAE).

Tympanometric Screening

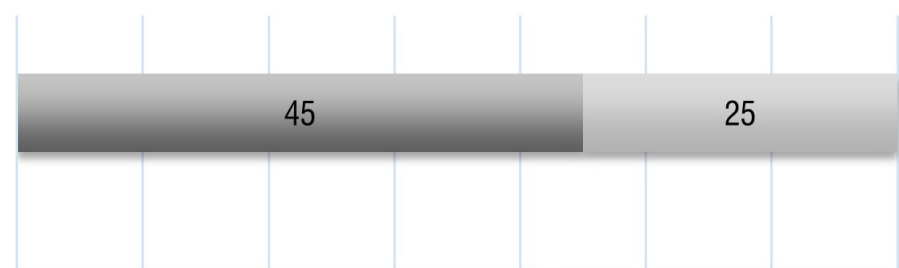

TEOAE Screening

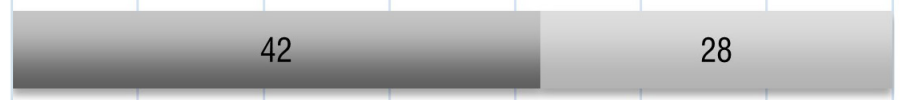

Audiometric Screening

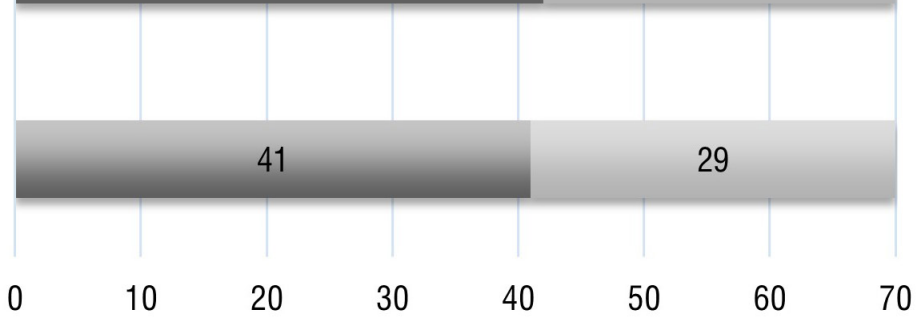

$$
\text { - Pass Fail }
$$

Labels: transient evoked otoacoustic emissions - TEOAE

Figure 2. Results of the different hearing screening protocols 
Table 1. Sensitivity, specificity, and predictive values for each procedure

\begin{tabular}{lccccc}
\hline & Sensitivity & Specificity & PPV & NPV & Accuracy \\
\hline Audiometric screening & $64.71 \%$ & $66.04 \%$ & $37.93 \%$ & $14.63 \%$ & $65.71 \%$ \\
Tympanometric screening & $64.71 \%$ & $73.58 \%$ & $44.00 \%$ & $13.33 \%$ & $71.43 \%$ \\
TEOAE & $66.67 \%$ & $69.23 \%$ & $42.86 \%$ & $14.29 \%$ & $68.57 \%$ \\
\hline
\end{tabular}

Labels: PPV - positive predictive value; NPV - negative predictive value; transient evoked otoacoustic emissions - TEOAE

\section{DISCUSSION}

In our study, TEOAE was the screening procedure with the best validity and accuracy. This method has been used before for the auditory screening of preschoolers and schoolchildren ${ }^{17,18}$. TEOAE had better accuracy when compared to other procedures, similar to another study ${ }^{16}$ that found $93.5 \%$ accuracy for conductive impairment with high specificity (94.6\%) and regular sensitivity $(77.3 \%)$. Studies in different parts of the world have been using TEOAE as a procedure for screening schoolchildren. They were applied to students from 3 to 18 years old in the Mozambican Audiology Program ${ }^{28}$, for instance. When assessing the viability of the TEOAE screening program in the age group of 6 to 12 years in Greece, researchers found $100 \%$ sensitivity in detecting impairments worse than $30 \mathrm{~dB}$ along with a $90 \%$ sensitivity and a $64 \%$ specificity in detecting impairments worse than $25 \mathrm{~dB}$. The PPV in that study was of $25 \%$, with a $98 \%$ NPV ${ }^{29}$ which are different from the values found in this study but indicate good TEOAE results.

Tympanometric screening has been included either as part of the screening protocol ${ }^{10,19}$ or as a single procedure $^{30}$ in Brazil. In a systematic review ${ }^{9}$ on the prevalence of hearing loss, the authors found less than $10 \%$ of studies including tympanometric procedures. High levels of tympanometric alterations have been previously reported in the literature and corroborate our finding regarding the high prevalence of conductive alterations. However, the tympanometric curve is used as the pass criterion rather than the tympanometric gradient ${ }^{10,19,30,31}$, although this measure may be useful in detecting otitis media with effusion (OME). A study comparing children and adolescents with and without OME found, in the former group, gradient values between 0.01 and $0.93 \mathrm{ml}^{32}$, thus agreeing with the $0.2 \mathrm{ml}$ criterion we adopted in this study as a signal of hearing screening failure.

Audiometric screening is also indicated for the school setting ${ }^{15,18}$. A study with schoolchildren using averages of $0.5,1$, and $4 \mathrm{kHz}$, as well as a 15
dB normality criterion, found a $24.6 \%$ prevalence of hearing loss in the sample ${ }^{31}$. Despite differences in criteria, this value is similar to that found in the present study. According to Prieve et al. (2015) ${ }^{18}$, audiometric screening may be less susceptible to transient middle ear conditions and may, therefore, be more reliable in detecting permanent hearing loss. Such results agree with the relationship between conductive alterations and TEOAE accuracy we found in the present study.

These economic and social conditions have important effects on health and diseases. Some factors contribute to illnesses, such as stress, living conditions during the early years, social exclusion, unemployment, and others ${ }^{29}$. There are also different types and degrees of hearing loss that could be influenced by these social determinants of health ${ }^{33}$. These conditions and inequalities are common in Brazil and could probably contribute with the frequent conductive problems in school age as we saw in our results and others ${ }^{17,19,20,26,34}$. Sensorineural hearing loss is also important but in this context, when TEOEA is used, it is possible to find fail result in both types of hearing loss, so this one could be a promising procedure in such environment. Also, it is crucial to structure the hearing health program for a school population ${ }^{35}$ by studying more about prevalence and associated factors of hearing loss ${ }^{36}$. In addition, it is key to study different hearing screening protocols to support that kind of program.

One limitation of this study is related to sensitivity, specificity and predictive values. The AAA (2011) ${ }^{15}$ guideline shows that the hearing screening protocol should identify at least $90-95 \%$ of individuals with hearing loss and fail no more than $5 \square 10 \%^{15}$. We probably had results influenced from our sample loss, which shows that we need more studies with that kind of methodology in different places. The guideline also indicates that pure tone screening has its limitations ${ }^{15}$, as we agree that so do all isolated procedures like the three procedures studied. However, when the sources are limited and there are different social determinants of health among the world population, there is a need 
to study different solutions as we see in diagnostic accuracy studies like this one. It is important to do more research with this population to understand the procedures.

In this study, the prevalence of hearing loss was considerably high (24.2\%). This hearing problems are similar to previous results obtained in other Brazilian cities, such as São Luís (MA) ${ }^{37}$ (24.3\% of children from 7 to 9 years old) and Goiânia (GO) (24\% of children from 7 to 14 years old) ${ }^{34}$. However, they are larger than those observed in other studies performed in more developed regions of Brazil26,36,38 and other countries $6,7,8,13,14$. The differences in prevalence rates are due, in part, to the great variability in the procedures, methods, and techniques of the auditory screening tests performed and in the adopted pass and fail criteria of these procedures $^{7,9}$. In addition to the difficulty to identify in each studied location the measures of immunization and prevention adopted that may be related to the prevalence rates $^{7}$, as well as the associated factors ${ }^{9}$, it is also observed that most prevalence studies use pure tone audiometry as a hearing screening procedure. Thus, the results obtained can be different if the next studies use TEOAE as a hearing screening procedure in schoolchildren. It is noteworthy that TEOAE is an electroacoustic and non-psychoacoustic examination, therefore it informs about the functioning of the peripheral auditory system. Yet, it does not contribute, in isolation, to differentiating conductive changes from sensorineural, which can also be a disadvantage in the Hearing Screening Program in Schoolchildren. On the other hand, the inclusion of TOAE in the hearing screening protocol can increase the accuracy and differentiate between conductive and sensorineural hearing loss, but it is difficult to implement it in mass screening performed in schools ${ }^{6}$ due to the increased cost of equipment and qualified professionals, as well as for the longer application time of the procedures.

Most etiologies that cause hearing loss in children are preventable $\mathrm{e}^{4}$ and, therefore, can be avoided as long as there is a hearing health program at different times in life focused on identifying hearing loss by using protocols with proven accuracy and cost-effectiveness. Thus, it becomes a routine procedure in the health care of schoolchildren, contributing both to the detection of congenital and acquired problems and avoiding the consequences and/or aggravations in child development ${ }^{6}$. This will allow to measure the hearing problem magnitude at school as well as understand and characterize these problems to determine measures of promotion, prevention, and intervention. School health management will only take place in the field of hearing health care, encompassing stages of identification, monitoring and referral, and intervention. An example of this aspect is related to conductive hearing loss caused by ear infections. By identifying this silent problem in children, notifying parents, and referring them for evaluation and treatment in the healthcare network, action is taken to solve the problem and avoid worsening hearing loss by preventing it from becoming permanent and/or of higher degree. It is also possible to analyze other similar cases in the school and to relate to the places where the children live to identify the source of the conductive problem in hearing, following up on collective health actions ${ }^{4}$.

Thus, it is important to perform clear recommendations and raise awareness about hearing loss to avoid it and reduce any future impact. The implementation of public health strategies to solve this problem will result in improved quality of life for children with hearing loss, as well as it may reduce the financial impact of uncorrected hearing loss ${ }^{4}$.

The results evidenced in this study also point that there is a need for further research comparing these conventional procedures of audiological clinics with technological innovations available in new generation equipment or available in applications for smartphones and tablets.

\section{CONCLUSION}

Among the three evaluated procedures, TEOAE had the best validity (sensitivity, specificity, and predictive values) for use in the school setting. Furthermore, it is characterized by shorter application times and greater acceptability among schoolchildren and can detect the most common causes of hearing impairment in the school context, although it has limitations in differentiating between conductive or sensorineural problems. If this is not the objective of the student's hearing health program identification stage, TEOAE may be a method of better validity when compared to pure tone audiometry and tympanometry.

\section{ACKNOWLEDGMENTS}

Our special thanks to Coordenação de Aperfeiçoamento de Pessoal de Nível Superior (CAPES) for the financial support, and to Ulli Amin Lauar and Roseane Santos Silva for their contribution to data collection and recording, as well as to the participants, their families and the school system. 


\section{REFERENCES}

1. Balbani APS, Montovani JC. Impacto das otites médias na aquisição da linguagem em crianças. $J$ Pediatr. 2003;79(5):391-6.

2. Oliveira OS, Penna LM, Lemos SMA. Language development and hearing impairment: literature review. Rev. CEFAC. 2015;17(6):2044-55.

3. Anne S, Lieu JEC, Cohen MS. Speech and language consequences of unilateral hearing loss: a systematic review. Am Acad Otolaryngol-Head Neck Surg. 2017;157:572-9. doi.org/10.1177/ 0194599817726326.

4. WHO. World Health Organization. (2018). Addressing the rising prevalence of hearing loss. World Health Organization. [cited 2020 Jun6]. Available from: https://apps.who.int/iris/ handle/10665/260336.

5. Instituto Brasileiro de Geografia e Estatística. Censo demográfico 2010: resultados gerais da amostra. Rio de Janeiro: IBGE, 2010.

6. Skarzynski H, Gos E, Swierniak W, Henryk $P$. Prevalence of hearing loss among polish school-age children from rural areas - results of hearing screening program in the sample of 67.416 children. I J Pediatr Otorhinol. 2020;128:109676.

7. Lieu JEC. Variations in the prevalence of hearing loss in children: truth or arti- fact? JAMA Otolaryngol. Head Neck Surg. 2017;143:935-6. doi. org/10. 1001/jamaoto.2017.1172.

8. Tingang EW, Noubiap JJ, Fokouo JVF, Oluwole OG, Nguefack S, Chumusa ER et al. Hearing impairment overview in Africa: the case of Cameroon. Genes. 2020;11:233. doi:10.3390/genes11020233.

9. Nunes ADS, Silva CRL, Balen SA, Souza DLB, Barbosa IR. Prevalence of hearing impairment and associated factors in school-aged children and adolescents: a systematic review. Braz J Otorhinolaryngol. 2019;85(2):244-53.

10. Colella-Santos MF, Bragato GR, Martins PMF, Dias $A B$. Triagem auditiva em escolares de 5 a 10 anos. Rev. CEFAC. 2009;11(4):644-53.

11. Choi JE, Ahn J, Park HW, Baek SY, Kim S, Moon IJ, Prevalence of minimal hearing loss in South Korea. PLoS One. 2017;12(2):e0171635.
12. Elbeltagy R. Prevalence of mild hearing loss in schoolchildren and its association with their school performance. Int Arch Otorhinolaryngol. 2020;24(1):e93-e98.

13. Gierek T, Gwóźdź-Jezierska M, Markowski J, Witkowska M. The assessment of hearing organ of school children in Upper Silesia region. Int J Pediatr Otorhinolaryngol. 2009;73(12):1644-9.

14. Al-Rowaily MA, AlFayez Al, AlJomiey MS, AlBadr AM, Abolfotouh MA. Hearing impairments among Saudi preschool children. Int J Pediatr Otorhinolaryngol. 2012;76(11);1674-7.

15. American Academy of Audiology. Childhood hearing screening guidelines. 2011. [cited 2012 Aug16]. Available from: http://www.cdc.gov/ ncbddd/hearingloss/documents/aaa_childhoodhearing-guidelines_2011.pdf.

16. Angrisani RMG, Suzuki MR, Pifaia GR, Sousa EC, Gil D, Azevedo MF. Triagem auditiva neonatal com emissões otoacusticas e reflexo cocleo-palpebral: estudo da sensibilidade e especificidade. Rev. CEFAC. 2012;14(5):844-52.

17. Vasconcelos RM, Serra LSM, Aragão VMF. Emissões otoacústicas evocadas transientes e por produto de distorção em escolares. Rev. Bras. Otorrinol. 2008;74(4):503-7.

18. Prieve BA, Schooling T, Venediktov R, Franceschini $\mathrm{N}$. An evidence-based systematic review on the diagnostic accuracy of hearing screening instruments for preschooland school-age children. Am J Audiol. 2015;24(2):250-67.

19. Cardoso YMP, Franceschini VR, Franceschini CN, Franceschini D, Franceschini AW, Reis RA et al. School hearing screening in the city of Porto Alegre: results of the pilot study. Rev. CEFAC. 2014;16(6):1878-87.

20. Tamanini D, Ramos N, Dutra LV, Bassanesi HJC. School-age hearing screening: identification of hearing impairments in first grade students. Rev. CEFAC. 2015;17(5):1403-14.

21. Mahomed-Asmail F, Swanepoel DW, Eikelboom RH. Hearing loss in urban South African school children (grade 1 to 3 ). Int $\mathrm{J}$ Pediatr Otorhinolaryngol. 2016;84:27-31.

22. Jayawardena A, Waller B, Edwards B, LarsenReindorf R, Esinam Anomah J, Frimpong B et al. Portable audiometric screening platforms used in low-resource settings: a review. J Laryngol Otol. 2019;133(2):74-9. doi.org/10.1017/ S0022215118001925. 
23. Sekhar DL, Zalewski TR, Paul IM. Variability of State School-Based Hearing Screening Protocols in The United States. J Community Health. 2013;38(3):569-74.

24. Hall JW. Effective and efficient pre-school hearing screening: essential for successful Early Hearing Detection and Intervention (EHDI). JEHDI. 2016;1(1):2-12.

25. Brasil. Ministérios da Educação e Saúde. Decreto № 6.286, de 5 de dezembro de 2007. Institui o Programa Saúde na Escola - PSE, e dá outras providências. [cited 2017 Oct8]. Available from: http://www.planalto.gov.br/ccivil_03/_ato20072010/2007/decreto/d6286.htm.

26. Balen SA, Debiasi TF, Pagnossim DF, Broca VC, Roggia SM, Gondim LM. Caracterização da audição de crianças em um estudo de base populacional no município de Itajaí/SC. Arq. Int. Otorrinolaringol. 2009;13(4):372-80.

27. Sousa LCA, Piza MRT, Alvarenga KF, Cóser PL. Emissões otoacústicas. In: Sousa LCA, Piza MRT, Alvarenga KF, Cóser PL (orsg). Eletrofisiologia da audição e emissões otoacústicas: princípios e aplicações clínicas. 2ed. São Paulo: Tecmed; 2008. p.109-30.

28. Clark JL. Hearing loss in Mozambique: current data from Inhambane province. Int $\mathrm{J}$ Audiol. 2008;47(1):S49-S56.

29. Georgalas C, Xenellis J, Tzangaroulakis A, Ferekidis E. Screening for hearing loss and middle-ear effusion in school-age children, using transient evoked otoacoustic emissions: a feasibility study. J Laryngol Otol. 2008;122(12):1299-304.

30. Lindau TA, Delecrode CR, Cardoso ACV. Tympanometric findings in a group of students. Rev. CEFAC. 2013;15(6):1453-60.

31. Yang T-H, Wu C-S, Liao W-H, Yeh K-C, Chou P. Mean hearing thresholds among school children in Taiwan. Ear Hear. 2011;32(2):258-65.

32. Duzer $S$, Akyigit A, Cetiner $H$. Values range of tympanometric gradient in otitis media with effusion. J Craniofac Surg. 2017;28(3):e283-e286.

33. Ceballos AGC, Cardoso C. Determinantes sociais de alterações fonoaudiológicas. Rev. Soc. Bras. Fonoaudiol. 2009;14(3):441-5.

34. Araújo SA, Moura JR, Camargo LA, Alves W. Avaliação auditiva em escolares. Rev Bras Otorrinolaringol. 2002;68(2):263-6.
35. Lacerda ABM L, Gondim LMA. Hearing Health Programs for schoolchildren. On J Otolaryngol \& Rhinol. 2019;1(4):1-3. OJOR.MS.ID.000519. DOI: 10.33552/OJOR.2019.01.000519.

36. Nunes ADS, Balen SA, Souza DLB, Barbosa IR. Prevalence of hearing loss and associated factors in school-age individuals in an urban area of northeast Brazil. Int Arch Otorhinolaryngol. 2020. (no prelo).

37. Vasconcelos RM, Monte MO, Aragão VMF, Silva BT. Alterações auditivas em crianças de 7 a 9 anos de idade de uma escola pública de ensino fundamental em São Luís, Maranhão. RBPS 2007;20(3):155-160, doi: 10.5020/18061230.2007.

38. Piatto VB, Maniglia JV. Hearing evaluation in children aged 3-6 years in day-care centers. J. Pediatr. 2001;77(2):124-30. 